\title{
Indoor radon concentration and gamma dose rate in dwellings of the Province of Naples, South Italy, and estimation of the effective dose to the inhabitants
}

\author{
M. Quarto ${ }^{1,2 \star}$, M. Pugliese ${ }^{1,2}$, F. Loffredo ${ }^{1,2}$ and V. Roca ${ }^{1,2}$ \\ 1 Dipartimento di Fisica, Università di Napoli Federico II, via Cintia, 80126 Naples, Italy. \\ 2 INFN - Sezione di Napoli, via Cintia, 80126 Naples, Italy.
}

Received 28 April 2015 - Accepted 16 October 2015

\begin{abstract}
The indoor radon concentration was measured in 471 dwellings in the Province of Naples. Radon concentration measurements were carried out using LR-115 passive alpha track detectors (SSNTDs) that were exposed for two consecutive semesters. The annual average radon concentration in the dwellings was found to vary from 21 to $722 \mathrm{~Bq} \mathrm{~m}^{-3}$ with an average value of $107 \pm 75 \mathrm{~Bq} \mathrm{~m}^{-3}$. In about $93 \%$ of the dwellings the radon concentrations were found to be below $200 \mathrm{~Bq} \mathrm{~m}^{-3}$, which is the recommended level by Italian law for new buildings. Simultaneously with the radon concentration measurements, indoor gamma dose rates were measured in 388 dwellings. Indoor gamma dose rates were measured using Thermoluminescent Dosimeters (TLDs) exposed in each dwelling for six months. The arithmetic mean value was found to be $327 \pm 102 \mathrm{nGy} \mathrm{h}^{-1}$, after the subtraction of the cosmic ray contribution. A weak correlation between the indoor radon concentration and gamma dose rate was found. The correlation between indoor radon measurements and gamma dose rates and the same building characteristics was also studied.
\end{abstract}

Keywords: radon / gamma dose rate / LR-115 detectors / TLD dosimeters

\section{Introduction}

Major exposure to ionizing radiation for the general population arises from terrestrial radiation and cosmic rays (UNSCEAR, 2000; Al-Saleh, 2007; Almgren et al., 2008). In particular, internal exposure due to radon and its progeny is responsible for more than $50 \%$ of the natural background dose to human beings, as reported by UNSCEAR (2000). Today, it is well known that exposure to indoor radon and its shortlived decay products contributes significantly to an increasing risk of lung cancer (Lubin et al., 2004; Bochicchio et al., 2005b; Darby et al., 2005; Krewski et al., 2005, 2006). After inhalation, radon is almost completely exhaled due to its long half-life (3.82 d) and being an inert gas, while its progenies, specially the two radon daughters with short half-lives, ${ }^{218}$ Po and ${ }^{214}$ Po, being electrically charged, can be attached to dust or smoke particles (aerosol) in indoor air. When these particles are inhaled, a fraction of them is deposited in the lungs, where they emit alpha particles that are absorbed in the nearby lung tissue, damaging the pulmonary epithelium and thereby increasing the probability of having lung cancer. Indoor exposure to radon daughters is considered responsible for $10-15 \%$ of the total cancer deaths in the USA (NRC, 1993). In Italy, the estimate of lung cancer deaths attributable to radon exposure was found to be about 10\% (Bochicchio et al.,

\footnotetext{
* maria.quarto@na.infn.it
}

2013). Worldwide, many investigations have been conducted to evaluate this kind of exposure in homes and to develop useful remediation. On the basis of recent epidemiological studies, the recent Council Directive (Euratom, 2013) reports a statistically significant increase in lung cancer risk from prolonged exposure to indoor radon at levels of the order of $100 \mathrm{~Bq} \mathrm{~m}^{-3}$ and it states that national action plans are needed to address long-term risks from radon exposure. The International Commission on Radiological Protection (ICRP, 1993) has established an action level between $200 \mathrm{~Bq} \mathrm{~m}^{-3}$ and $600 \mathrm{~Bq} \mathrm{~m}^{-3}$. Based on the review of the epidemiological studies on cohorts of miners and population-based case-control studies, ICRP Publication 115 (ICRP, 2010) determined a new nominal risk coefficient of $8 \times 10^{-10} \mathrm{~Bq} \mathrm{~h} \mathrm{~m}{ }^{-3}$ and with this value, an annual dose of about $20 \mathrm{mSv}$ per year can be calculated by $600 \mathrm{~Bq} \mathrm{~m}^{-3}$. So, the Commission, in the associated Statement on Radon (2009), revised the reference level for the radon concentration in dwellings from $600 \mathrm{~Bq} \mathrm{~m}^{-3}$ to $300 \mathrm{~Bq} \mathrm{~m}^{-3}$. ICRP Publication 126 (ICRP, 2014) questioned the protection strategy against radon based on the distinction between protection approaches for dwellings and workplaces (ICRP, 1993, 2007) and now recommends an integrated approach for protection against radon exposure in all buildings, whatever their purpose and the status of their occupants. This strategy is based on an optimization principle below a derived reference level set in terms of the concentration in 
air. The national authorities are encouraged to set a reference level in the range $100-300 \mathrm{~Bq} \mathrm{~m}^{-3}$, taking the prevailing economic and societal circumstances into account. In Italy there is no legislation for protection against exposure to radon in dwellings; currently, only the elaboration of a legislative proposal to that effect is part of the National Radon Plan (PNR) (Ministry of Health, 2002). Today, it is assessed that the majority of inhabitants in urban areas spends about $80 \%$ of their time indoors, so their exposure to ionizing radiation from building materials could be relevant (UNSCEAR, 2000). In Italy, only one national survey has been carried out that investigated the radon concentrations and gamma dose rate in dwellings in the early '90s. Subsequently, in the Province of Naples, other studies were performed to determine the radon concentration in homes and workplaces (Pugliese et al., 2013, 2014; Quarto et al. 2013, 2014). In this study, simultaneous measurements of the radon activity concentration and gamma dose rate in some dwellings of the Province of Naples are shown. In this region, in particular in the coastal area, where some active volcanoes are present, the concentrations of undifferentiated pyroclastic rock are elevated. These materials, very rich in uranium and thorium traces, widely used in house construction, make the natural radiation exposure particularly significant. Moreover, the statistical relationship between the radon concentration and gamma dose rate and some building characteristics such as the age of the dwelling, main building materials and floor level were analyzed.

\section{Materials and methods}

\subsection{Radon specific activity measurements}

Radon measurements were carried out with LR-115 passive alpha track detectors (SSNTDs). The choice of dwellings to be monitored was not carried out with a random sampling, but it was based on our convenience and the availability of the inhabitants. However, the monitored houses were very different in building materials, age of construction and the floor of the monitored room. In each dwelling the detector was exposed in the room where the inhabitants spent most of their time, generally the living room and bedroom, for two consecutive semesters in order to obtain a concentration averaged over the whole year. Homeowners were asked to fill out a questionnaire containing details about their lifestyle and dwelling characteristics. The questionnaires, returned with the track detectors and TLDs, provided information on the type of dwelling, age of dwelling, floor of the room where the detectors were placed, type of major building materials, and type of materials lining the walls and the floor. After exposure all detectors were chemically etched using a solution of $2.5 \mathrm{~N} \mathrm{NaOH}$ at $60^{\circ} \mathrm{C}$ for $110 \mathrm{~min}$. For LR-115 detectors, the number of tracks increases linearly as the residual thickness decreases. So, it is necessary to determine the residual thickness to normalize the observed track density to the nominal final thickness $(6.5 \mu \mathrm{m})$. The residual thickness was determined by acquiring the image of the detector by means of a scanner with double lighting and its mean brightness in the gray scale was determined using suitable software for image processing ${ }^{1}$. Using a previously de-

\footnotetext{
${ }^{1}$ ImageJ software: Image Processing and Analysis in Java, version 1.46r, National Institutes of Health, USA.
}

termined calibration curve, the brightness was then converted into residual thickness The automatic counting of tracks was also performed using the ImageJ software. The radon activity concentration was calculated using the formula:

$$
C_{R n}=\frac{N}{E \times T}
$$

where $N$ is the track density corrected by the background and normalized to the nominal thickness of $6.5 \mu \mathrm{m}, E$ the calibration factor and $T$ the exposure time. The Lower Limit of Detection (LLD) of the method was estimated to be $4 \mathrm{~Bq} \mathrm{~m}^{-3}$. The quality assurance of the whole method was performed by participating in the intercomparison exercise organized by the German Federal Office for Radiation Protection (BfS). The participation in the intercomparison showed that the results were included in the good category with an uncertainty of $12 \%$ with respect to the references (data not published). Moreover, the Laboratory of Radioactivity (LaRa) has accreditation according to ISO (2008) and the European Standard (ISO/IEC, 2005) for an "Integrated measurement method for determining the average activity concentration of radon 222 in the environmental air using passive sampling and delayed analysis" (ISO, 2012).

\subsection{Gamma dose rate measurements}

Measurements of the indoor gamma dose rate were carried out simultaneously with the radon measurements in 388 houses. Measurements were performed using TLDs exposed for six months in the same position where the LR-115 detectors were placed. In this survey, LiF:Mg,Ti (TLD 100) chips were used due to their low cost, high sensitivity and low fading. When ionizing radiation hits a TL material, electrons are freed from some atoms and moved to other parts of the material, leaving behind "holes" of positive charge. Subsequently, when the TL material is heated, the electrons and the "holes" re-combine, and release the extra energy in the form of light. The light intensity can be measured, and related to the amount of energy initially absorbed. Calibration of the TLD 100 was carried out using a photon beam with an average energy of $3 \mathrm{MeV}$ at the LINAC of the Istituto Tumori "Fondazione Pascale" of Naples. The TLDs were exposed to doses ranging between $0.2-1.2 \mathrm{~Gy}$, for which the thermoluminescence (TL) glow curves were recorded and the areas of the main peak were determined. A calibration curve between the dose rate and TL intensity was built and the calibration factor of $4.3 \pm 0.4 \mathrm{nC} \mathrm{mGy}^{-1}$ was determined. After exposure, all TLDs were read between $100{ }^{\circ} \mathrm{C}$ and $300{ }^{\circ} \mathrm{C}$ using a heating rate of $10{ }^{\circ} \mathrm{C} \mathrm{s}^{-1}$ with a TL reader (Harshaw 3500). For the gamma dose rate measurements, the LaRa has accreditation according to ISO (2008).

\subsection{Statistical analysis}

For each dwelling, in order to obtain annual values, the time-weighted average radon concentration from two consecutive semesters was calculated using the exposure time, expressed in days, as a weight. The normality of the logtransformed data was tested by the Shapiro-Wilk test and the 


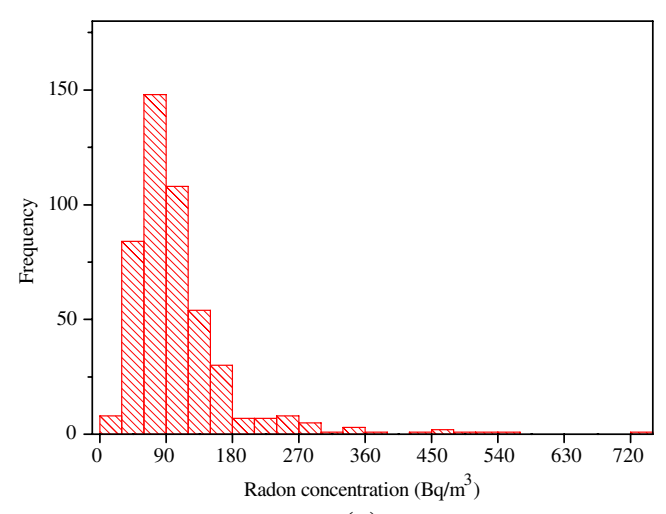

(a)

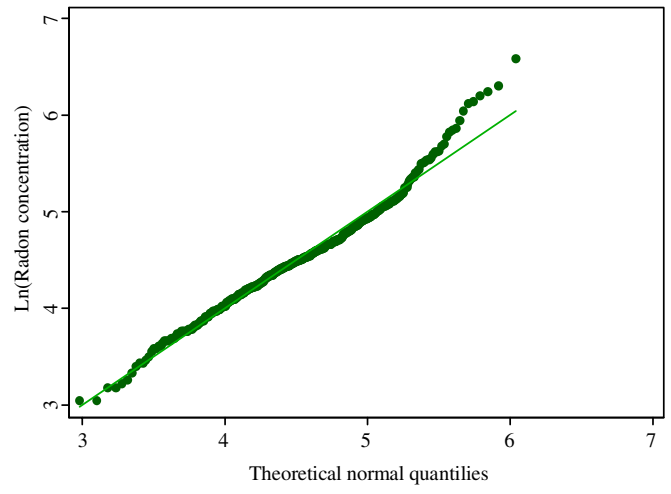

(b)

Figure 1. (a) Frequency distribution of radon concentrations in dwellings of province of Naples; (b) Q-norm plot of natural log-transformed radon concentration.

homogeneity of variance was tested by Bartlett's test. The comparison between pairs of groups was performed by means of Student's t-test, while the comparisons among multiple groups were performed by Analysis of Variance (ANOVA). The significance of difference between groups was evaluated with Bonferroni's post-hoc test. The relationship between the indoor gamma dose rate and radon concentration was analyzed using Pearson's correlation. All statistical analyses were performed using Stata software (Stata Corp, College Station, TX, USA).

\section{Results and discussion}

\subsection{Indoor radon activity concentrations}

The frequency distribution of the annual radon concentrations measured in the 471 dwellings is reported in Figure 1a. The experimental data show an approximately log-normal distribution, although the Shapiro-Wilk test failed to assess the normality ( $p$-value $<0.001$ ) because of the departure from normality of the data distribution's upper tail (Figure 1b). The radon concentration measured in the entire investigated area ranged from 21 to $722 \mathrm{~Bq} \mathrm{~m}^{-3}$, with an arithmetic mean of $107 \pm 75 \mathrm{~Bq} \mathrm{~m}^{-3}$ and a geometric mean of $91 \mathrm{~Bq} \mathrm{~m}^{-3}$. The average radon activity concentration measured in the present survey is higher than the Italian national average, which is $75 \mathrm{~Bq} \mathrm{~m}^{-3}$ and Campanian average, which is $95 \mathrm{~Bq} \mathrm{~m}^{-3}$ (Bochicchio et al., 2005a). This result is attributable to the fact that the soil of the Province of Naples is very rich in pozzolan and tuff with respect to other places in the Campania region and other regions of Italy. Eighty-six percent of the monitored dwellings were single-family houses, $9 \%$ were in multistorey buildings with less than 10 dwellings and only $5 \%$ were in multistorey buildings with more than 10 dwellings. Forty-four percent of the dwellings were built mainly of bricks and stone, $23 \%$ of concrete and $30 \%$ of tuff. About $26 \%$ of the monitored rooms were placed on the ground floor/in the basement, while $35 \%$ were on the first floor, and $38 \%$ on a floor higher than the first floor.

The results show that in $93 \%$ of houses, the radon concentrations are below $200 \mathrm{~Bq} \mathrm{~m}^{-3}$, which is the recommended level of Italian legislation for new buildings, and only $1 \%$ are
Table 1. Analysis of variance of the indoor radon activity concentration by major factor.

\begin{tabular}{lccccc}
\hline Floor level & $\boldsymbol{N}$ & $\begin{array}{c}\text { Range } \\
\left(\mathbf{B q ~ m}^{-3}\right)\end{array}$ & $\begin{array}{c}\text { GM } \\
\left(\mathbf{B q ~ m}^{-3}\right)\end{array}$ & GSD $p$-value \\
\hline Basement and ground floor 121 & $36-546$ & 111 & 1.6 & \\
First floor & 163 & $21-513$ & 91 & 1.6 & $<0.001$ \\
Second or higher floor & 176 & $21-722$ & 80 & 1.7 & \\
Year of construction & & & & & \\
Before 1919 & 81 & $21-463$ & 116 & 1.8 & \\
1919-1960 & 104 & $31-546$ & 109 & 1.6 & $<0.001$ \\
After 1960 & 274 & $21-722$ & 79 & 1.6 & \\
Main building & & & & & \\
materials & & & & & \\
Concrete & 101 & $28-722$ & 90 & 1.8 & \\
Stone, bricks & 196 & $21-463$ & 83 & 1.7 & $<0.001$ \\
Tuff & 131 & $21-420$ & 107 & 1.7 & \\
\hline
\end{tabular}

$\mathrm{GM}=$ geometric mean; $\mathrm{GSD}=$ geometric standard deviation; $p$ value $=$ significance level observed for analysis of variance for comparing among groups.

higher than $400 \mathrm{~Bq} \mathrm{~m}^{-3}$ which is the recommended level of Italian legislation for old buildings. Currently in Italy there is no mandatory program for the implementation of remediation actions of homes where the radon concentration exceeds recommended levels. Consequently, in the absence of a law, only individual interventions are made by public agencies or individuals sensitive to the issue.

It is well known that indoor radon concentrations are generally affected by several factors such as the age of the dwelling, kind of floor, building materials, etc. and so the effects of these building characteristics on the radon levels were examined. In Table 1, descriptive statistics of radon activity concentrations and their analysis of variance (ANOVA) by major factor are reported. The analysis of variance was applied to the log-transformed data after checking in all cases the homogeneity of the variances within the groups to be compared with the Barlett test.

As shown in Table 1, the one-way analysis of variance on the log-transformed data presents a statistically significant 


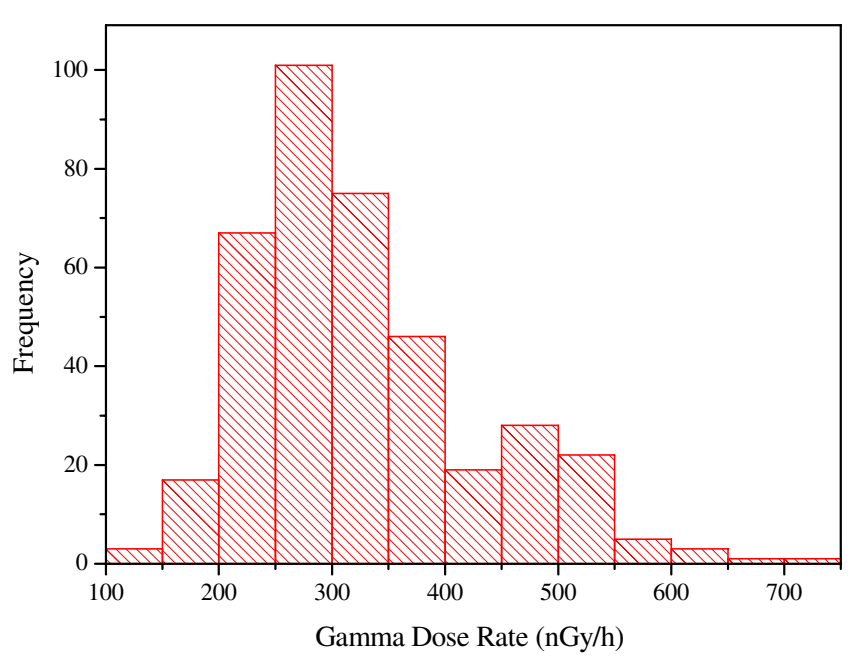

Figure 2. Frequency distribution of indoor gamma dose rate in dwellings of province of Naples.

dependence on the floor $(p<0.001)$. The Bonferroni posthoc test indicated that the radon concentration of basements and ground floors were higher than those measured in the first and upper floors. Building materials are the second source for indoor radon due to ${ }^{226} \mathrm{Ra}$ content and the exhalation rate of radon from materials. For this reason, an analysis of the influence of different building materials on radon concentration was performed. Data were grouped into three categories based on the different materials: i) concrete, ii) stone and brick, and iii) tuff. The ANOVA analysis showed that the highest radon concentrations correspond to dwellings made of tuff and the difference between houses built with different materials is statistically significant $(p<0.001)$. Also, the influence of the age of the building on radon specific activity was estimated by grouping the houses into three categories i) built before 1919, ii) built between 1919-1960, and iii) built after 1960 . The ANOVA analysis demonstrated that the annual radon concentrations are significantly higher for older houses compared with those built after 1960 ( $p<0.001)$. The higher values reported for older houses could be explained by the fact that the ventilation rate in older houses is less than the new ones because they generally have smaller or fewer windows. Moreover, in the old buildings there is not good air tightness between the soil and first floor.

\subsection{Indoor gamma dose rate}

The frequency distribution of the gamma dose rate in air from terrestrial sources measured in the 388 houses is shown in Figure 2. The gamma dose rate indicates a normal-like distribution although the Shapiro-Wilks test failed to assess normality $(p<0.001)$. The fraction related to terrestrial sources was estimated by subtracting from the total value the contribution of the cosmic component, using Sakellariou's model (Sakellariou et al., 1995). The arithmetic mean was found to be $327 \pm 102 \mathrm{nGy} \mathrm{h}^{-1}$, while the lowest value measured was $136 \mathrm{nGy} \mathrm{h}^{-1}$ and the highest $702 \mathrm{nGy} \mathrm{h}^{-1}$. The mean value of the indoor gamma dose rate obtained is higher than the
Table 2. Statistical analysis of influence of major factors on the gamma dose rate.

\begin{tabular}{lcccc}
$\begin{array}{l}\text { Main building } \\
\text { materials }\end{array}$ & $N$ & $\begin{array}{c}\text { Range } \\
\left(\mathbf{n G y ~ h}^{-1}\right)\end{array}$ & $\begin{array}{c}\mathbf{A M} \pm \mathbf{S D} \\
\left(\mathbf{n G y ~ h}^{-1}\right)\end{array}$ & $\boldsymbol{p}$-value \\
\hline Concrete & 59 & $152-593$ & $299 \pm 80$ & \\
$\begin{array}{l}\text { Stone, bricks } \\
\text { Tuff }\end{array}$ & 37 & $216-524$ & $322 \pm 71$ & $<0.05$ \\
$\begin{array}{l}\text { Materials lining } \\
\text { the floor }\end{array}$ & & & & \\
\hline Tile & $258-506$ & $354 \pm 65$ & \\
Wood & 10 & $136-622$ & $304 \pm 88$ & \\
Granite & 13 & $267-388$ & $321 \pm 36$ & \\
Marble & 46 & $158-515$ & $315 \pm 88$ & \\
Materials lining & & & & \\
the walls & & & & \\
Wallpaper & 88 & $136-587$ & $355 \pm 104$ & \\
Plaster & 269 & $136-701$ & $316 \pm 701$ & $<0.05$ \\
\hline
\end{tabular}

$\mathrm{AM}=$ arithmetic mean; $\mathrm{SD}=$ standard deviation; $p$-value $=$ significance level observed in the analysis of variance for comparing groups and Student's t-test.

national average, which is $105 \pm 10 \mathrm{nGy} \mathrm{h}^{-1}$ (Bochicchio et al., 1996a).

This result could be due to the presence of active volcanoes in the coastal area of the Province of Naples, with the consequence of an elevated presence of undifferentiated pyroclastic rocks (Ortolani and Pagliuca, 1987), widely used in building construction.

The main source of indoor gamma radiation is the building materials and the materials lining the walls and floors of the rooms. To assess the effect of these factors on the gamma dose rate measured, the dwellings were categorized into three groups according to the main building materials: cement, brick and stone, and tuff. The ANOVA analysis shows that the mean values of the indoor gamma rate were significantly different for dwellings with different main building materials. The results of the analysis of factors affecting the gamma dose rate are reported in Table 2.

The Bonferroni post-hoc test shows that the mean values of the indoor gamma dose rate are significantly higher for dwellings built of tuff compared with those constructed of concrete $(p<0.001)$, while no statistically significant difference was found between the gamma dose rate measured in houses built of tuff and those built of brick and stone. The materials lining the walls are plaster and wallpaper, while for the floors the materials used are tiles, wood, granite and marble. The statistical analysis (ANOVA) revealed no significant differences among the various coating materials of floors $(p=0.2030)$, while Student's t-test shows that houses with walls covered in wallpaper have an average level of gamma dose rates greater than those with walls made of plaster.

In order to find a relationship between the indoor radon concentrations and indoor gamma dose rates, correlation analysis between these two variables measured in the same room was analyzed and is reported in Figure 3. A correlation coefficient of 0.1921 was found, which indicates a very weak 


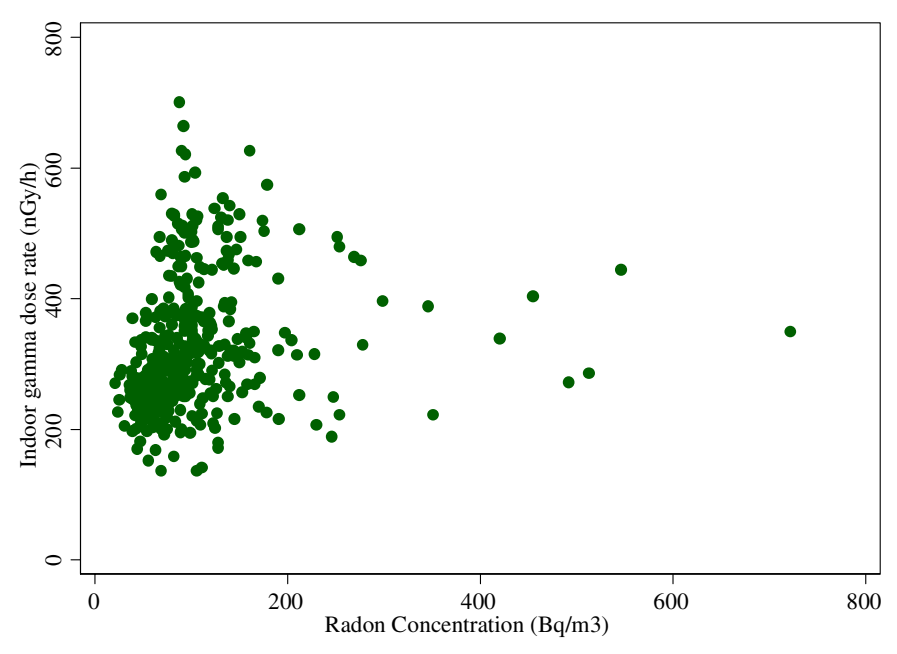

Figure 3. Scatter plot of indoor gamma dose rate versus indoor radon activity concentration for 388 dwellings where simultaneous measurements of radon concentrations and gamma dose rate were performed in the Province of Naples.

positive correlation. Because the indoor radon concentration and gamma dose rate have different distribution, a log conversion was applied to the radon concentration: in this case, the correlation coefficient becomes 0.052 . Applying the statistical Fisher test to the linear regression model between the two variables, a $p$-value $<0.01$ was obtained, which shows that the model used may explain a significant proportion of the variance of the phenomenon.

The results show that the highest values of the gamma dose rate were measured in correspondence with values of radon that were relatively not high $\left(<200 \mathrm{~Bq} \mathrm{~m}^{-3}\right)$. This finding might suggest that radon and its progeny contribute little to the gamma dose in air. Some authors (Iimoto et al., 2001; Sundal and Strand, 2004; Pilkyte and Buktus, 2005; Kurnaz et al., 2011) report that the indoor radon concentration has a coarse correlation with the gamma dose rate; the reason for the difference could be attributed to the high ventilation rate in the dwellings, but unfortunately, this information was not collected during the survey.

\subsection{Radiological effect estimates of the indoor gamma dose rate and radon}

To evaluate the effective dose received by the adult population, the UNSCEAR model (2000) was used, that assumes an indoor occupancy factor of 0.8 and a conversion coefficient of $0.7 \mathrm{~Sv} \mathrm{~Gy}{ }^{-1}$. The annual effective dose was calculated by the following equation:

$$
H_{\text {gamma }}=D \times T \times C \times O
$$

where $H_{\text {gamma }}$ is the annual effective dose from the indoor gamma dose rate $\left(\mathrm{mSv} \mathrm{y}^{-1}\right), D$ the indoor gamma dose rate in $\mathrm{nGy} \mathrm{h}^{-1}, T$ the time in hours $\left(8760 \mathrm{~h} \mathrm{y}^{-1}\right), C$ the conversion coefficient $\left(0.7 \mathrm{~Sv} \mathrm{~Gy}^{-1}\right)$ and $O$ the occupancy factor $(0.8)$.

The estimated annual effective dose by the gamma dose rate in air was found to be $1.6 \mathrm{mSv} \mathrm{y}^{-1}$, which is higher than the Italian national average $(0.4) \mathrm{mSv} \mathrm{y}^{-1}$ (Bochicchio et al., 1996a). Moreover, taking into account the UNSCEAR model, the annual effective dose to the general population due to radon was calculated using the following formula:

$$
H_{\text {radon }}=C_{\mathrm{Rn}} \times F \times O \times T \times C
$$

where $H_{\text {radon }}$ is the annual effective dose from indoor radon, $C_{\mathrm{Rn}}$ the indoor radon activity concentration in $\mathrm{Bq} \mathrm{m}^{-3}, F$ the equilibrium factor (0.4), $O$ the occupancy factor $(0.8), C$ the dose conversion coefficient $\left(1.4 \times 10^{-8} \mathrm{mSv}\right.$ per $\left.\mathrm{Bq} \mathrm{m}^{-3} \mathrm{~h}\right)$ and $T$ the time in hours $\left(8760 \mathrm{~h} \mathrm{y}^{-1}\right)$.

The dose conversion coefficient reported in formula (3) is obtained by equating the lung cancer risk of $8 \times$ $10^{-10}$ per $\mathrm{Bq} \mathrm{m}{ }^{-3} \mathrm{~h}$ with the total detriment for the general population reported in ICRP Publication 103 (2007), which is $5.7 \times 10^{-2} \mathrm{~Sv}^{-1}$. The dose coefficient obtained using the lung cancer risk reported in ICRP Publication 103 is approximately double that obtained with the value reported in ICRP Publication 65 (1993) and about 1.5 times that reported in UNSCEAR (2000). In this study, the annual effective dose due to indoor radon was found to change from 0.8 to $18.2 \mathrm{mSv} \mathrm{y}^{-1}$ with an average of $4.2 \mathrm{mSv} \mathrm{y}^{-1}$. These values are higher than the Italian national average value, which is $1.2 \mathrm{mSv} \mathrm{y}^{-1}$ (Bochicchio et al., 1996b).

\section{Conclusion}

In this study, the indoor radon concentration and indoor gamma dose rate were investigated in some dwellings of the Province of Naples, South Italy. For radon, values of $107 \mathrm{~Bq} \mathrm{~m}^{-3}$ and $91 \mathrm{~Bq} \mathrm{~m}^{-3}$ for the arithmetic and geometric mean, respectively, were found. For the gamma dose rate, a mean value of $327 \mathrm{nGy} \mathrm{h}^{-1}$ was found. A weak correlation was found between the indoor radon activity concentration and indoor gamma dose rate. The results show a relationship between radon concentrations and some building characteristics such as the age of dwellings, floor of the room monitored and building materials. Moreover, the indoor gamma dose rate was influenced by building materials, but no correlation was found with the coating materials of floors. The average value for the annual effective dose due to radon was found to be $4.2 \mathrm{mSv} \mathrm{y}^{-1}$, based on the estimated annual radon activity concentration, while the annual effective dose due to indoor gamma exposure was found to be $1.6 \mathrm{mSv} \mathrm{y}^{-1}$.

\section{References}

Almgren S., Isaksson M., Barregard L. (2008) Gamma radiation doses to people living in Western Sweden, J. Environ. Radioact. 99, 394-403.

Al-Saleh F.S. (2007) Measurements of indoor gamma radiation and radon concentrations in dwellings of Riyadh city, Saudi Arabia, Appl. Radiat. Isotopes 65, 843-848.

Bochicchio F., Campos Venuti G., Monteventi F., Nuccetelli C., Piermattei S., Risica S., Tommasino L., Torri G. (1996a) Indoor Exposure to Gamma Radiation in Italy. In: Proceeding of the International Congress of the International Radiation Protection Association (IRPA 9), Vienna, Austria 2, 190-192. 
Bochicchio F., Campos Venuti G., Nucciatelli C., Piermattei S., Risica S., Tommasino L., Torri G. (1996b), Results of the representative italian national survey on radon indoors, Health Phys. 71, 721-748.

Bochicchio F., Campos Venuti G., Piermattei S., Nuccetelli C., Risica S., Tommasino L., Torri G., Magnoni M., Agnesod G., Sgorbati G., Bonomi M., Minach L., Trotti F., Malisan M.R., Maggiolo S., Gaidolfi L., Giannardi C., Rongoni A., Lombardi M., Cherubini G., D’Ostilio S., C. Cristofaro, M. Pugliese, V. Martucci, A. Crispino, P. Cuzzocrea, A. Sansone Santamaria, Cappai M. (2005a) Annual average and seasonal variations of residential radon concentration for all the Italian Regions, Radiat. Meas. 40, 686-694.

Bochicchio F., Forastiere F., Farchi S., Quarto M., Axelson O. (2005b) Residential radon exposure, diet and lung cancer: A case-control study in a Mediterranean region, Int. J. Cancer 114, 983-991.

Bochicchio F., Antignani S., Venoso G., Forastiere F. (2013) Quantitative evaluation of the lung cancer deaths attributable to residential radon: A simple method and results for all the 21 Italian Regions, Radiat. Meas. 50, 121-126.

Darby S., Hill D., Auvinen A., Barros-Dios J.M., Baysson H., Bochicchio F., Deo H., Falk R., Forastiere F., Hakama M., Heid I., Kreienbrock L., Kreuzer M., Lagarde F., Makelainen I., Muirhead C., Oberaigner W., Pershagen G., Ruano-Ravina A., Ruosteenoja E., Schaffrath A., Tirmarche M., Tomascaronek L., Whitley E., Wichmann H.E., Doll R. (2005) Radon in homes and lung cancer risk: collaborative analysis of individual data from 13 European case-control studies, Br. Med. J. 330, 223-226.

Euratom (2013) Council Directive 2013/59/Euratom 5 December 2013.

Iimoto T., Kosako T., Sugiura N. (2001) Measurements of summer radon and its progeny concentrations along with environmental gamma dose rate in Taiwan, Environ. Radioact. 57, 57-66.

ICRP Publication 65 (1993) Protection Against Radon-222 at Home and at Work, Ann. ICRP 23 (2).

ICRP Publication 103 (2007) The 2007 Recommendations of the International Commission on Radiological Protection, Ann. ICRP 37 (2-4).

ICRP (2009) Statement on Radon ICRP Ref 00/902/09.

ICRP Publication 115 (2011) Lung Cancer Risk from Radon and Progeny and Statement on Radon, Ann. ICRP 40 (1).

ICRP Publication 126 (2014) Radiological Protection against Radon Exposure, Ann. ICRP 43 (3).

ISO/IEC (2005) ISO/IEC 17025: General requirements for the competence of testing and calibration laboratories.

ISO (2008) ISO 9001: Quality management systems - Requirements.

ISO (2012) ISO 11665-4: Measurement of radioactivity in the environment - Air: radon-222 - Part 4: Integrated measurement method for determining average activity concentration using passive sampling and delayed analysis.
Krewski D., Lubin J.H., Zielinski J.M., Alavanja M., Catalan V.S., Field R.W., Klotz J.B., Létourneau E.G., Lynch C.F., Lyon J.I., Sandler D.P., Schoenberg J.B., Steck D.J., Stolwijk J.A., Weinberg C., Wilcox H.B. (2005) Residential radon and risk of lung cancer: a combined analysis of 7 north american casecontrols studies, Epidemiology 16 (2), 137-145.

Krewski D., Lubin J.H., Zielinski J.M., Alavanja M., Catalan V.S., Field R.W., Klotz J.B., Létourneau E.G., Lynch C.F., Lyon J.L., Sandler D.P., Schoenberg J.B., Steck D.J., Stolwijk J.A., Weinberg C., Wilcox H.B. (2006) A combined analysis of North American case-control studies of residential radon and lung cancer, J. Toxicol. Environ. Health A 69 (78), 533-597.

Kurnaz A., Kucukomeroglu B., Cevik U., Celebi N. (2011) Radon level and gamma doses in dwellings of Trabzon, Turkey, Appl. Radiat. Isotopes 69, 1554-1559.

Lubin J.H., Wang Z.Y., Boice J.D.J., Zhao Y.X., Blot W.J., De Wang L., Kleinerman R.A. (2004) Risk of lung cancer and residential radon in China: pooled results of two studies, Int. J. Cancer 109, 132-137.

Ministry of Health Piano Nazionale Radon (PNR), 2002, in Italian.

National Research Council (1993) Health effects of exposure to radon. Committee on the Biological Effects of Ionizing Radiations.

Ortolani, F., Pagliuca, S. (1987) Relationships Between Volcanism and Structures in Campania During the Quaternary, Rendiconto dell'Accademia delle scienze fisiche e matematiche di Napoli Special Issue, 215-231.

Pilkyte L., Butkus D. (2005) Influence of gamma radiation of indoor radon decay products on absorbed dose rate, J. Environ. Eng. Land. Manag. 13 (2) 65-72.

Pugliese M., Quarto M., De Cicco F., De Sterlich C., Roca V. (2013) Radon Exposure Assessment for Sewerage System's Workers in Naples, South Italy, Indoor and Built Environ. 22(3), 575-579.

Pugliese M., Quarto M., C., Roca V. (2014) Radon concentrations in air and water in the thermal spas of Ischia Island, Indoor and Built Environ. 23 (6), 823-827.

Quarto M., Pugliese M., Loffredo F., Roca V. (2013) Indoor radon concentration measurements in some dwellings of the Penisola Sorrentina, South Italy, Radiat. Prot. Dosim. 156 (2), 207-212.

Quarto M., Pugliese M., Loffredo F., Zambella C., Roca V (2014) Radon measurements and effective dose from radon inhalation estimation in the Neapolitan catacombs, Radiat. Prot. Dosim. 158 (4), 442-446.

Sakellariou K., Angelopoulos A., Sakelliou L., Sandilos P., Sotiriou D., Proukakis Ch. (1995) Indoor gamma radiation measurements in Greece, Radiat. Prot. Dosim. 60 (2) 177-180.

Sundal A.V., Strand T. (2004) Indoor gamma radiation and radon concentrations in Norwegian carbonate area, J. Environ. Radioact. 77, 175-189.

UNSCEAR (2000) Sources, effects and risk of ionizing radiation. Report to General Assembly with scientific Annexes United Nations.

Cite this article as: M. Quarto, M. Pugliese, F. Loffredo, V. Roca. Indoor radon concentration and gamma dose rate in dwellings of the Province of Naples, South Italy, and estimation of the effective dose to the inhabitants. Radioprotection 51(1), 31-36 (2016). 